\title{
Influence of Medicinal Spices on the Acid Tolerance of a Health Beneficial Bacterium Streptococcus thermophilus ST-M5
}

\author{
Margie M. Sánchez-Vega ${ }^{1}$, Kayanush J. Aryana ${ }^{1,2 *}$ \\ ${ }^{1}$ School of Animal Sciences, Louisiana State University, Baton Rouge, USA \\ ${ }^{2}$ Department of Food Science, Louisiana State University, Baton Rouge, USA \\ Email: *karyana@agcenter.lsu.edu
}

Received July 11, 2012; revised August 10, 2012; accepted August 21, 2012

\begin{abstract}
There is a great deal of public interest in the use of herbal remedies. Garlic is said to antiviral and antifungal and along with ginger; they are antibacterial and preventatives for cardiovascular diseases. Ginger is very effective against nausea and has analgesic properties. Onion reduces the risk of developing diabetes and like garlic, has anticancer properties. Streptococcus thermophilus is a lactic acid bacterium that produces lactase, which facilitates the digestion of lactose in milk, decreases the symptoms of malabsorption, and reduces the risk of antibiotic associated diarrhea. Acid tolerance is an important probiotic characteristic and it is an indication of the ability of the microorganism to withstand the acidic $\mathrm{pH}$ of the stomach. Freshly thawed culture was inoculated in acidified MRS broth at $\mathrm{pH} 2$ and 1\% v/v of freshly extracted spice juice was added. Control was without spice juice. Growth was determined hourly during 2 hours of incubation at $37^{\circ} \mathrm{C}$. Bacterial culture treated with all three spices individually showed a significant increase in counts at 0 and 1 hours of incubation when compared to control. After 2 hours of incubation, culture exposed to ginger showed no significant difference compared to control, while there were slight yet significantly lower counts for culture exposed to garlic and onion individually. Among the spices, ginger had the best overall effect. These three spices can be used with Streptococcus thermophilus enabling health benefits from both sources.
\end{abstract}

Keywords: Spices; Garlic; Ginger; Onion; Acid Tolerance; Streptococcus thermophilus

\section{Introduction}

Some medicinal plants are used as spices. Garlic (Allium sativum) is said to be antibacterial, antiviral and antifungal [1] and also prevent cardiovascular diseases [2] and some types of cancer [3]. Ginger (Zingiber officinale) is effective against nausea [4] and cardiovascular diseases [5] and is also an analgesic and has antibacterial properties [6]. Onion (Allium cepa) is effective against the common cold [7] and reduces the risk of developing diabetes [8]; it also has anti-inflammatory [9], anti-cholesterol [10], anticancer [11] and antioxidant [9] properties.

Functional foods are foods that have a health benefit over and above their regular counterparts [12]. In 2009, the US was the second largest market for functional foods, with a worth of $\$ 7.123$ billion dollars. It is estimated to be worth $\$ 8.618$ billion dollars in 2015 [13]. The importance of a balanced diet and the presence of probiotic bacteria in the gut are well recognized in maintaining general gut health [14].

${ }^{*}$ Corresponding author.
Streptococcus thermophilus is a lactic acid bacterium commonly used in yogurt manufacture. This bacterium replicates within the human gastrointestinal tract and produces lactase, which facilitates the digestion of lactose in milk [15]. It also can decrease the symptoms of malabsorption, which often go along with acute infections diarrhea and it reduces the risk of antibiotic associated diarrhea [16].

Probiotics are microorganisms introduced orally in the gastrointestinal tract that are able to contribute positively to the activity of intestinal microflora and, therefore, to the host health [17]. The term probiotic means "for life" and it is currently used to name bacteria associated with beneficial effects for humans and animals [18]. Probiotic microorganisms should be capable of surviving passage through the digestive tract, be resistant to gastric juices, be capable to proliferate in the gut and be able to grow in the presence of bile under intestinal conditions [17]. When a probiotic reaches the stomach, it is exposed to an acidic solution that contains hydrochloric acid, potassium chloride and sodium chloride, which brings the stomach 
$\mathrm{pH}$ to a range between 1 and 2 [19,20]. In view of the fact that the stomach acid is one of the first stress barriers encountered by the probiotics upon ingestion, it is very important that the probiotic be acid tolerant. Whether or not spices with medicinal properties have the capacity of enhancing the acid tolerance of Streptococcus thermophilus is not known. The objective of this study was to elucidate the influence of spices with medicinal properties namely, garlic, ginger and onion on the acid tolerance of Streptococcus thermophilus a health beneficial bacterium.

\section{Materials and Methods}

\subsection{Experimental Design}

Freshly thawed Streptococcus thermophilus ST-M5 (F-DVS, Chr. Hansen's Laboratory, Milwaukee, WI) culture was suspended in sterilized $0.1 \%$ peptone water and $1 \%$ of freshly extracted spice juice (garlic, ginger or onion) was added. The three spice juice treatments were performed in a random manner. The control was the sample in which no spice juice was added. Acid tolerance was determined by plating the control and the treated samples every hour for 2 hours of incubation. The experimental design was a completely randomized design (CRD). Three replications were conducted for each experimental condition.

\subsection{Sample Preparation}

Fresh spices were peeled, washed and dried. Using a juice extractor, (JM480S, Juiceman), the juice of each spice was obtained just before it was needed and it was added immediately to the inoculated peptone water. This step was done in this manner to avoid oxidation reactions. Control and spice treated samples for acid tolerance analysis were prepared by inoculating $11 \mathrm{~mL}$ of freshly thawed culture of Streptococcus thermophilus ST-M5 (Chr. Hansen's Laboratory, Milwaukee, WI) into $99 \mathrm{~mL}$ of sterile acidified MRS broth at $\mathrm{pH} 2$ containing $1 \mathrm{~mL}$ juice of each spice (garlic or ginger or onion).

\subsection{Preparation of Media}

\subsection{1. pH Modified MRS Broth}

The MRS broth was prepared according to the manufacturer's instructions (Difco ${ }^{\mathrm{TM}}$, Dikinson and Company, Sparks, MD). The $\mathrm{pH}$ of the broth was adjusted to 2 using $10 \mathrm{M} \mathrm{HCl}$.

\subsubsection{Streptococcus thermophiles Agar}

The appropriate amount of distilled water was added to a 1L graduated cylinder. The ingredients used to make $S$. thermophilus agar were weighed (10 g of Bacto Tryptone (Becton, Dickinson and Co, Sparks, MD), $10 \mathrm{~g}$ of Sucrose
(Amresco, Solon, OH), $5 \mathrm{~g}$ of Bacto yeast extract (Becton, Dickinson and Co, Sparks, MD), 2 g of K2HPO4 (Fisher Scientific, Fair Lawn, NJ) per L using individual plastic weighing boats and transferred to a $1 \mathrm{~L}$ Erlenmeyer flask. The mix was stirred to dissolve the ingredients. The $\mathrm{pH}$ was adjusted to $6.8 \pm 0.1$ with $\mathrm{HCl} 10 \mathrm{M}$. Next, $6 \mathrm{~mL}$ of $0.5 \%$ bromocresol purple solution and 12 $\mathrm{g}$ of agar were added to the medium. The medium was autoclaved at $121^{\circ} \mathrm{C}$ for 15 minutes.

\subsection{Acid Tolerance}

The acid tolerance was determined according to the method proposed by Pereira and Gibson [21] with slight modifications. The bacterial culture Streptococcus thermophilus ST-M5 was inoculated in acidified MRS broth (Difco, Becton, Dickinson and Co, Sparks, MD) previously adjusted to $\mathrm{pH} 2$ using $10 \mathrm{M} \mathrm{HCl}$. The inoculated acidified MRS broth was incubated aerobically at $37^{\circ} \mathrm{C}$. At 0,1 and 2 hours of inoculation, $11 \mathrm{~mL}$ of the inoculated broth were serially diluted in $99 \mathrm{~mL}$ of $0.1 \%$ peptone water and $1 \mathrm{~mL}$ of each dilution was pour plated using Streptococcus thermophilus agar [22]. The Petri dishes were incubated aerobically at $37^{\circ} \mathrm{C}$ for 48 hours after which the colonies were counted.

\subsection{Statistical Analysis}

Differences of least square means were used to determine significant differences at $\mathrm{P}<0.05$ for main effects (spice and time), and two way interaction effects (spice * time). Data is presented as mean \pm standard error of the means. Significant differences were determined at $\alpha=0.05$. Significant differences $(\mathrm{P}<0.05)$ among the main effects were analyzed using Tukey's adjustment. Data was analyzed using Proc Mixed model of Statistical Analysis System $\left(\mathrm{SAS}^{\circledR}\right)$.

\section{Results and Discussion}

The acid tolerance of Streptococcus thermophilus ST-M5 as influenced by various health beneficial spice juices was tested and is shown in Figure 1.

All three spices showed a significant $(P<0.05)$ increase in counts at 0 hours of incubation when compared to control. After 1 hour of incubation, all three spices had significantly $(\mathrm{P}<0.05)$ higher counts than the control. After 2 hours of incubation, ginger showed no significant ( $\mathrm{P}>0.05$ ) difference compared to control (5.5176 Log $\mathrm{cfu} / \mathrm{mL}$ ), while there were slight yet significantly lower counts for garlic (4.2579 Log cfu/mL) and onion (5.0709 Log cfu/mL) (Table 1).

Mean log reduction of the viable counts of $S$. thermophilus subjected to different spice juices were obtained by subtracting counts at 2 hours from 0 hours and are shown in Table 2. 


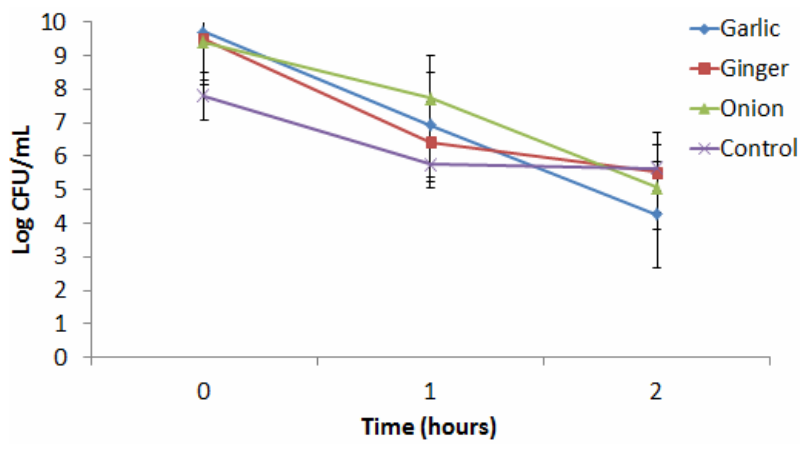

Figure 1. Acid tolerance of Streptococcus thermophilus STM5 under the influence of garlic, ginger and onion juice.

Table 1. Pr > F of acid tolerance of Streptococcus thermophilus ST-M5 exposed to different spice juices to control.

\begin{tabular}{cccc}
\hline Treatment (spice) & $\mathbf{0 ~ h r}$ & $\mathbf{1} \mathbf{~ h r}$ & $\mathbf{2} \mathbf{~ h r}$ \\
\hline Garlic & $<0.001$ & $<0.001$ & $<0.001$ \\
Ginger & $<0.001$ & $<0.001$ & 0.9571 \\
Onion & $<0.001$ & $<0.001$ & $<0.001$ \\
\hline
\end{tabular}

Table 2. Mean log reduction of the viable counts of Streptococcus thermophilus ST-M5 when exposed to spice juice for 2 hours.

\begin{tabular}{cc}
\hline Treatment (spice) & Log CFU/mL \\
\hline Garlic & 5.4522 \\
Ginger & 3.9684 \\
Onion & 4.3373 \\
Control & 2.1431 \\
\hline
\end{tabular}

In Table 2, a high number indicates high bacterial death and a lower number indicates low bacterial death. The log reduction of ginger showed the lowest bacterial death when compared with the rest of the spices.

An important characteristic of a probiotic is its survival at low $\mathrm{pH}$ [23]. A protective coating of exopolysaccharides (EPS) may allow the bacterium to better withstand stomach acid and bile salts [24]. According to a study by Boke et al. [25], it was demonstrated that EPS protected the bacteria in gastrointestinal conditions and they suggest that the bacterial EPSs are thought to play a role in the protection of microbial cells against low $\mathrm{pH}$, like that of the stomach.

Mater and others [26] reported that $S$. thermophilus by itself resisted a $\mathrm{pH}$ as low as 2 and 2.5 and maintained its viability. Furthermore, Lick and others [27] found that Streptococcus thermophilus is able to survive gastrointestinal passage in vivo and detected viable counts in human duodenal samples after fresh yogurt ingestion.

\section{Conclusion}

Among the spices, ginger had the best overall effect, showing the lowest bacterial death, while garlic showed the highest, but still with viable counts. These three spices can be used with Streptococcus thermophilus enabling health benefits from both sources.

\section{REFERENCES}

[1] R. Gupta, B. Thakur, H. B. Singh, V. D. Sharma, V. M. Katoch and S. V. S. Chauhan, "Anti-Tuberculosis Activity of Selected Medicinal Plants against Multi-Drug Resistant Mycobacterium Tuberculosis Isolates,” The Indian Journal of Medical Research, Vol. 131, No. 6, 2010, pp. 809-813.

[2] K. Rahman, "Historical Perspective on Garlic and Cardiovascular Disease,” The Journal of Nutrition, Vol. 131, No. 3, 2001, pp. 977S-979S.

[3] C. H. Kaschula, R. Hunter and M. I. Parker, "GarlicDerived Anticancer Agents: Structure and Biological Activity of Ajoene," International Union of Biochemistry and Molecular Biology, Vol. 36, No. 1, 2010, pp. 78-85.

[4] A. Keating and R. A. Chez, "Ginger Syrup as an Antiemetic in Early Pregnancy," Alternative Therapies in Health and Medicine, Vol. 8, No. 5, 2002, pp. 89-91.

[5] M. H. Liang, "From America: Cookbook Medicine or Food for Thought: Practice Guidelines Development in the USA," Annals of the Rheumatic Diseases, Vol. 51, No. 11, 1992, pp. 1257-1258. doi:10.1136/ard.51.11.1257

[6] K. L. Grant and R. B. Lutz, "Alternative Therapies: Ginger,” American Journal of Health-System Pharmacy, Vol. 57, No. 10, 2000, pp. 945-947.

[7] A. K. Meena, B. Singh, A. K. Yadav, U. Singh, R. Kaur, A. Sachan, Kiran, V. Gautam and B. Pal, "Review on Medicinal Properties and Bioactive Constituents of Herbal Spices Commonly Used in India,” Journal of Pharmacy Research, Vol. 3, No. 4, 2010, pp. 866-868.

[8] K. Srinivasan, "Plant Foods in the Management of Diabetes Mellitus: Spices as a Beneficial Antidiabetic Food Adjuncts," International Journal of Food Sciences and Nutrition, Vol. 56, No. 6, 2005, pp. 399-414. doi:10.1080/09637480500512872

[9] J. Sanderson, W. R. Mclauchlin and G. Williamson, "Quercetin Inhibits Hydrogen Peroxide-Induces Oxidation of the Rat Lens," Free Radical Biology and Medicine, Vol. 26, No. 5-6, 1999, pp. 639-645. doi:10.1016/S0891-5849(98)00262-7

[10] T. Kaneko and N. Baba, "Protective Effect of Flavonoids on Endothelial Cells against Linoleic Acid Hydroperoxidase-Induced Toxicity," Bioscience, Biotechnology and Biochemistry, Vol. 63, No. 2, 1999, pp. 323-328. doi:10.1271/bbb.63.323

[11] S. Kawaii, Y. Tomono, E. Katase, K. Ogawa and M. Yano, "Antiproliferative Activity of Flavonoids on Several Cancer Cell Lines,” Bioscience, Biotechnology and Biochemistry, Vol. 63, No. 5, 1999, pp. 896-899. doi:10.1271/bbb.63.896

[12] J. K. Nelson, “What Are Functional Foods?” 2010. http://www.mayoclinic.com/health/functional-foods/AN0 2088

[13] S. Starling, "US Functional Foods Market to Grow 21 Per 
Cent by 2015,” 2010.

http://www.nutraingredients-usa.com/Consumer-Trends/ US-functional-foods-market-to-grow-21-per-cent-by-2015

[14] J. Sutherland, M. Miles, D. Hedderly, J. Li, S. Devoy, K. Sutton and D. Lauren, "In Vitro Effects of Food Extracts on Selected Probiotic and Pathogenic Bacteria,” International Journal of Food Sciences and Nutrition, Vol. 60, No. 8, 2009, pp. 717-727. doi:10.3109/09637480802165650

[15] K. Beauchamp, "Yogurt Prevents Antibiotic-Associated Diarrhea,” Bastyr Center for Natural Health, 2004. http://bastyrcenter.org/content/view/914

[16] P. Marteau, B. Flourie, P. Pochart, C. Chastang, J. F. Desjeaux and J. C. Rambaud, "Effect of the Microbial Lactase (EC 3.2.1.23) Activity in Yogurt on the Intestinal Absorption of Lactose: An in Vivo Study in Lactase-Deficient Humans," The British Journal of Nutrition, Vol. 64, No. 1, 1990, pp. 71-79. doi:10.1079/BJN19900010

[17] FAO/WHO, "Probiotics in Food: Health and Nutritional Properties and Guidelines for Evaluation. Expert Consultation on Evaluation of Health and Nutrition Properties of Probiotics in Food Including Powder Milk with Live Lactic Acid Bacteria,” 2001. ftp://ftp.fao.org/docrep/fao/009/a0512e/a0512e00.pdf

[18] M. Saarela, L. Lähteenmäki, R. Crittenden, S. Salminen and T. Mattilda-Sandholmm, "Gut Bacteria and Health Foods-The European Perspective,” International Journal of Food Microbiology, Vol. 78, No. 1-2, 2002, pp. 99117. doi:10.1016/S0168-1605(02)00235-0

[19] E. Lindström, D. Chen, P. Norlén, K. Andersson and R. Håkanson, "Control of Gastric Acid Secretion: The Gastrin-ECL Cell-Parietal Cell Axis,” Comparative Biochemistry and Physiology-Part A: Molecular \& Integrative Physiology, Vol. 128, No. 3, 2001, pp. 503-511. doi:10.1016/S1095-6433(00)00331-7

[20] R. Fuller, "Probiotics in Human Medicine,” Gut, Vol. 32, No. 4, 1991, pp. 439-442. doi:10.1136/gut.32.4.439

[21] D. I. A. Pereira and G. R. Gibson, “Cholesterol Assimila- tion by Lactic Acid Bacteria and Bifidobacteria Isolated from the Human Gut," Applied and Environmental Microbiology, Vol. 68, No. 9, 2002, pp. 4689-4693. doi:10.1128/AEM.68.9.4689-4693.2002

[22] R. I. Dave and N. P. Shah, "Evaluation of Media for Selective Enumeration of Streptococcus thermophilus, Lactobacillus bulgaricus ssp. bulgaricus, Lactobacillus acidophilus, and Bifidobacteria,” Journal of Dairy Science, Vol. 79, No. 9, 1996, pp. 1529-1538. doi:10.3168/jds.S0022-0302(96)76513-X

[23] M. Brink, S. D. Todorov, J. H. Martin, M. Senekal and L. M. T. Dicks, "The Effect of Prebiotics on Production of Antimicrobial Compounds, Resistance to Growth at Low $\mathrm{pH}$ and in the Presence of Bile, and Adhesion of Probiotic Cells to Intestinal Mucus," Journal of Applied Microbiology, Vol. 100, No. 4, 2006, pp. 813-820.

[24] C. M. Roberts, W. F. Fett, S. F. Osman, C. Wijey, J. V. O’Connor and D. G. Hoover, "Exopolysaccharide Production by Bifidobacterium longum BB-79," Journal of Applied Microbiology, Vol. 78, No. 5, 1995, pp. 463-468. doi:10.1111/j.1365-2672.1995.tb03085.x

[25] A. Gulcin, A. Belma and B. Hatice, "The Role of Resistance to Bile Salts and Acid Tolerance of Exopolysaccharides (EPSS) Produced by Yogurt Starter Bacteria," Archives of Biological Sciences, Vol. 62, No. 2, 2010, pp. 323-328.

[26] D. G. Mater, L. Bretigny, O. Firmesse, M.-J. Flores, A. Mogenet, J.-L. Bresson and G. Corthier, "Streptococcus thermophilus and Lactobacillus delbreukii subsp. bulgaricus Survive Gastrointestinal Transit of Healthy Volunteers Consuming Yoghurt,” FEMS Microbiology Letters, Vol. 250, No. 2, 2005, pp. 185-187. doi:10.1016/j.femsle.2005.07.006

[27] S. Lick, K. Drescher and K. J. Heller, "Survival of Lactobacillus delbrueckii subsp. bulgaricus and Streptococcus thermophilus in the Terminal Ileum of Fistulated Göttingen Minipigs,” Applied and Environmental Microbiology, Vol. 67, No. 9, 2001, pp. 4137-4143. doi:10.1128/AEM.67.9.4137-4143.2001 